\title{
Vector Autoregressive (VAR) Model for Rain-Fall Forecasting in West Java Indonesia at the Peak of the Rainy Season
}

\author{
Imaduddin Al Rusman, Budi Nurani Ruchjana, Sukono
}

\begin{abstract}
Rain is a natural event that occurs in every region. Rainfall intensity in several regions that are close together indicates the same rainfall pat-tern each year, especially during the peak of the rainy season. Time series modeling that uses more than one variable can be used to see the relationship between the rainfall patterns. Vector Autoregressive (VAR) is a multivariate time series method that is used to see the relation-ships between variables and to forecast. The data that is used in this study are monthly rainfall data at the peak of the rainy season (December, January, February) in three locations in West Java, namely Bandung City, Cimahi City, and West Bandung Regency with a period of time from December 1981 February 2017. Based on the results of the analysis, it shows the similarity of rainfall patterns from the three locations based on plot data and high correlation values between locations. The appropriate VAR model is VAR(3) based on the smallest AIC value and has an average MAPE value 18,817 percent.
\end{abstract}

Index Terms: Rainfall, VAR, AIC, MAPE, Forecasting.

\section{INTRODUCTION}

According to the West Java Central Bureau of Statistics (2018), geographically, West Java has an area 35,377.76 $\mathrm{km} 2$ and the aver-age rainfall ranges from $2000 \mathrm{~mm}$ per year. The pattern of rainfall in West Java is included in the Monsoon pattern, which means the rainy season occurs from October to March and the peak of the rainy season occurs around January [2]. The intensity of high rain-fall can have negative impacts, such as floods and landslides. Although rainfall is not the main factor causing the disaster, but if rain-fall can be predicted, it will be able to help the government and the community to prepare themselves as a precaution if there is a high intensity of rainfall. In general, rainfall forecasting is done using the ARIMA and SARIMA methods which are univariate time series models. However, in fact there is a possibility of a relationship of rainfall in several regions that are close together. One of the multivariate time series forecasting methods is the Vector Autoregressive (VAR) model. VAR is a system of dynamic equations, with the estimation of a variable in a given period depending on the movement of these variables and other

Revised Manuscript Received on April 25, 2019.

Imaduddin Al Rusman, Master of Mathematics Program, Universitas Padjadjaran, Bandung, Indonesia.

Budi Nurani Ruchjana, Department of Mathematics, Universitas Padjadjaran, Bandung, Indonesia.

Sukono, Department of Mathematics, Universitas Padjadjaran, Bandung, Indonesia. variables involved in the system in previous periods [3].There are many studies that use the VAR model for forecasting, they are [6] using the VAR model to forecast rainfall and isohyet mapping in Semarang, [12] using the VAR model for forecasting rainfall in Indramayu, [7] constructing the VAR model for predicting ENSO, [9] applies the VAR model for rainfall and groundwater level analysis, and [5] uses the VAR mod-el to analyze trends in climate and malaria variability in Ghana. Based on the description above, this study will predict rainfall at the peak of the rainy season (December, January and February) in a multivariate manner. This is done because of the suspicion that rainfall in an area has a similar pattern with rainfall in other regions. The rainfall locations to be analyzed are three regencies / cities in West Java, namely Bandung City, Cimahi City, and West Bandung Regency with the aim of describing rainfall patterns and forecasting of the VAR model that has been obtained for several future periods.

\section{THEORETICAL STUDY}

\section{A. Stationary}

A time series data is stationary if the average, variance and auto-covariance values are constant over time. In other words, that three standard are not depending at time. Stationary data is data whose variance is not too large and has a tendency to approach the average value [3]. The stationary data in the mean on the time series modeling can be seen visually through the ACF plot. The ACF plot that falls slowly indicates that the data is not stationary in the mean. In addition, stationary test in the average can also use the unit root Augmented Dickey Fuller (ADF) test by calculating the test statistics, namely,

$t_{h i t}=\frac{\hat{\gamma}}{\operatorname{se}(\hat{\gamma})}$

where $\hat{\gamma}$ is the estimated value $\gamma$ and $s e(\hat{\gamma})$ standard deviation of $\gamma$. If the ADF t-statistic value is smaller than McKinnon's critical value, or the value of the significance level is smaller than the confidence level $(\alpha)$ then the data does not contain unit root or in other words the data is stationary.

\section{B. Model Identification}

Model identification is done to determine the order $\mathrm{p}$ of the model. The Partial 
Autocorrelation Function (PACF) is a simple function in determining order $p$. Suppose the model is known as follows: $Z(t+s)=\Phi_{s, 1} Z(t+s-1)+\Phi_{s, 2} Z(t+s-2)+\Lambda$

$$
+\Phi_{s, s} Z(t)+a_{s, t+s}(t)
$$

with $a_{s, t+s}(t)$ is an error component and $\Phi_{s, k}$ is the coefficient matrix of $m \times m, k=1,2, \mathrm{~K}, s$, will minimize $E\left\lfloor\left|Z(t+s)-\Phi_{s, 1} Z(t+s-1)++\Lambda+\Phi_{s, s} Z(t)\right|^{2}\right\rfloor$

by minimizing the equations above, obtained the general equation of Yule-Walker multivariate as follows

$\left[\begin{array}{cccc}\Gamma(0) & \Gamma^{\prime}(1) & \Lambda & \Gamma^{\prime}(s-1) \\ \Gamma(1) & \Gamma(0) & \Lambda & \Gamma^{\prime}(s-2) \\ \mathrm{M} & \mathrm{M} & \mathrm{O} & \mathrm{M} \\ \Gamma(s-1) & \Gamma(s-2) & \Lambda & \Gamma(0)\end{array}\right]\left[\begin{array}{c}\Phi_{s, 1}^{\prime} \\ \Phi_{s, 2}^{\prime} \\ \mathrm{M} \\ \Phi_{s, s}^{\prime}\end{array}\right]=\left[\begin{array}{c}\Gamma(1) \\ \Gamma(2) \\ \mathrm{M} \\ \Gamma(s)\end{array}\right]$

where $\Phi_{s, s}^{\prime}$ is function on lag $s$, and called PACF. For $\operatorname{AR}(p)$ $\operatorname{PACF} \Phi_{s, s}^{\prime} \neq 0$, for $k \leq p$, and $k>p$ in the other words $\mathrm{PACF}$ of $\operatorname{AR}(p)$ has 'cut off' after lag $p$.

\section{Vector Autoregressive (VAR) Model}

The Vector Autoregressive (VAR) model is an oncoming of quantitative forecasting that can be applied to multivariate time series data. This model explains the interrelationship between observations on certain variables at a time and observations on the variables themselves at previous times, and also their relation to observations of other variables at previous times. The general form of the $\operatorname{VAR}(p)$ model with $\mathrm{N}$ variables can be written as follows [14]:

$$
Z_{(N \times 1)}(t)=\sum_{j=1}^{p} \Phi_{(N \times N)}(j) Z_{(N \times 1)}(t-j)+a_{(N \times 1)}(t)
$$

with $\Phi_{(N \times N)}(j)$ is parameter of VAR model, and $a_{(N \times 1)} \sim \operatorname{iid} N\left(0, \sigma^{2}\right)$. Order $(p)$ expresses many past periods that affect the model output plus residuals.

\section{Estimation and Parameter Significance Test}

Ordinary Least Square (OLS) method is a method that is used to estimate parameters by minimizing the sum of square of error, $\sum_{i=1}^{n} \varepsilon_{i}^{2}$. The formula for parameter estimation is:

$\hat{\beta}=\left(X^{\prime} X\right)^{-1}\left(X^{\prime} Y\right)$

where $\hat{\beta}$ is parameter estimation, $\mathrm{X}$ is dependent variable, $X^{\prime}$ is independent variable transpose, and $Y$ is independent variable.

A model is said to be a good model if the parameters are estimated to be significant or the parameter values are not equal to zero. In general, testing the significance of parameters can be done partially (t test) and simultaneously ( $F$ test). Partial testing of parameter significance ( $\mathrm{t}$ test) is formulating the statistical hypothesis:

$H_{0}: \hat{\phi}_{i}=0$ (parameter coefficient is meaningless);

$H_{0}: \hat{\phi}_{i} \neq 0$ (parameter coefficient means).

Calculate test statistics: $t_{h i t}=\frac{\hat{\phi}}{\operatorname{se}(\hat{\phi})}$

with $\operatorname{se}(\hat{\phi})$ is an error standard of estimated value $\hat{\phi}$. Reject $H_{0}$ if $|t| \geq t_{\left(\frac{\alpha}{2}, n-p-1\right)}$ or $p$-value $\leq \alpha$ which means all parameters are partially significant for the model, where $n$ is the number of observations, and $\mathrm{p}$ is the number of parameters estimated.

For the stage of testing the parameter significance simultaneously ( $F$ test) is to formulate the statistical hypothesis:

$H_{0}: \hat{\phi}_{i}=0$ (parameter coefficient is meaningless);

$H_{0}: \hat{\phi}_{i} \neq 0$ (parameter coefficient means).

Calculate test statistics:

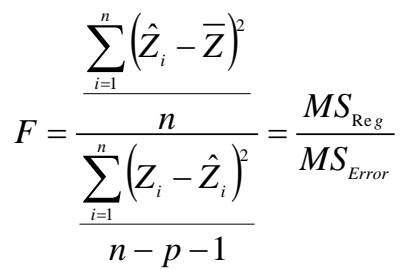

with $M S_{\text {Reg }}$ is Means of Square Regression, $M S_{\text {Error }}$ is Means of Square Error, $n$ is the number of observations, and $p$ is the number of parameters estimated. Rejected $H_{0}$ if $F \geq F_{(\alpha ; n ; n-p-1)}$ or $p$-value $\leq \alpha$ which means all parameters simultaneously significant to the model.

\section{E. Grange Causality Test}

Granger Causality Test is used to see the relationship between the two variables. Whether it has a relationship in the same direction, two directions, or no relationship at all. The Granger Causality Test Method is:

$I_{t}=\sum_{i=1}^{m} a_{i} I_{t-i}+\sum_{j=1}^{n} b_{j} Y_{t-j}-\mu_{t}$

$Y_{t}=\sum_{i=1}^{r} c_{i} I_{t-i}+\sum_{j=1}^{s} d_{j} Y_{t-j}-v_{t}$

where $\mu_{t}$ and $v_{t}$ is error term which is assumed not to contain serial correlation, and $m=n=r=s$. Based on the regression results of the two forms model of the equation above will produce four possibilities regarding the regression coefficient values of these equations as follows:

1. If $\sum_{j=1}^{n} b_{j} \neq 0$ and $\sum_{j=1}^{s} d_{j}=0$, then there is one way causality from $Y$ to $X$.

2. If $\sum_{j=1}^{n} b_{j}=0$ and $\sum_{j=1}^{s} d_{j} \neq 0$, then there is one way causality from $X$ to $Y$.

3. If $\sum_{j=1}^{n} b_{j}=0$ and $\sum_{j=1}^{s} d_{j}=0$, then there is no causality between $Y$ and $X$.

4. If $\quad \sum_{j=1}^{n} b_{j} \neq 0 \quad$ and 
$\sum_{j=1}^{s} d_{j} \neq 0$, then there is two way causality between $Y$

and $X$

To strengthen the indication of the existence of a form of causality as explained, it must be done $F$ test for each regression model.

\section{F. Model Diagnostic Test}

\section{Test for White Noise Residual}

The diagnostic test model is an examination of whether the model assumptions are met. One assumption that must be fulfilled is $\{Z(t)\}$ white noise. White noise means that the residuals of the model are uncorrelated, with zero averages and constant variances. Detection of residual white noise can be done by re-modeling the residuals obtained from the model. If the smallest AIC value is in the 0th lag, it can be said that there is no correlation between residuals, it means that the residuals are white noise. The statistical test for residual white noise is Portmanteau lack of fit test which is the development of the Ljung Box Test [13] with the following hypothesis:

$H_{0}: E\left(\varepsilon_{t}, \varepsilon_{t-i}\right)=0$, (the residual satisfy white noise);

$H_{1}$ : there is at least one $E\left(\varepsilon_{t}, \varepsilon_{t-i}\right)=0$, (the residual not satisfy white noise).

The test statistics that is used are:

$Q=n(n+2) \sum_{k=1}^{K}(n-k)^{-1} \hat{\rho}_{k}^{2}$

with $n$ is number of sample $\hat{\rho}_{k}^{2}$ is autocorrelation in $k$-th lag, and $K$ is the number of lags tested. Statistics $Q$ follow distribution $\chi_{(K-m)}^{2}$ where $m=p+q, p$ and $q$ are each order the ARMA model. Residual are white noise, $H_{0}$ is accepted, if $Q<\chi_{(K-m)}^{2}$ or $p$-value $>\alpha$.

\section{Heteroscedasticity Test}

Heteroscedasticity is a basic assumption that is the condition in which the variance of each residual term is constant or different. If this condition is not achieved, each observation will have different degrees of reliability. This causes the estimation process to be inefficient, while if it is still done the results are consistent and unbiased.

Residual Homoscedasticity test uses the ARCH-LM test. The hypothesis for the ARCH test is as follows:

$H_{0}$ : the residual squares do not show heteroscedasticity;

$H_{1}$ : residual squares indicate heteroscedasticity.

The ARCH-LM test is done by regressing the square of the residual model $\left(\varepsilon_{t}^{2}\right)$ so that the following estimates are obtained:

$$
\begin{aligned}
& \varepsilon_{t}^{2}=\phi_{0}+\phi_{1} \varepsilon_{t-1}^{2}+\Lambda+\phi_{q} \varepsilon_{t-q}^{2}+v_{t} \\
& L M=T \times R^{2}
\end{aligned}
$$

where $T$ is number of observations, $R^{2}$ is coefficient of determination from the regression model $\varepsilon_{t}^{2}$, and $q$ is the number of observations that affect. If $L M$ is greater than $\chi_{q}^{2}$, indicates an ARCH effect [3].

\section{G. Best Model Selection Criteria}

The selection of the best models generally uses two criteria, namely in sample and out sample. In sample criteria use Akaike's Information Criterion (AIC), while the out sample criteria by observe the value of Mean Absolute Percentage Error (MAPE). The following is explained about each of the best model selection criteria.

\section{Akaike's Information Criterion}

[1] introduced Akaike 's Information Criterion (AIC) for the best model selection criteria by considering the number of parameters in the model, which are based on the smallest (minimum) AIC value among the existing models. AIC can be formulated as follows [13]:

$A I C(M)=-2 \ln (\max$ likelihood $)+2 M$

with $M$ is number of parameter in the model. For ARMA model with the number of observations $n$, the log-likelihood function is as follows:

$\ln (L)=-\frac{n}{2} \ln \left(2 \pi \sigma_{a}^{2}\right)-\frac{1}{2 \pi \sigma_{a}^{2}} S(\phi, \mu, \theta)$

by maximizing the equation above, it will be obtained:

$\ln (\hat{L})=-\frac{n}{2} \ln \left(\hat{\sigma}_{a}^{2}\right)-\frac{n}{2}(1+\ln (2 \pi))$

because $\frac{n}{2}(1+\ln (2 \pi))$ is constant, then AIC criteria can be simplified to be:

$A I C(M)=n \ln \left(\hat{\sigma}_{a}^{2}\right)+2 M$.

The optimal order of the model is chosen based on the value of $M$ which is a function of $p$ and $q$, resulting in a minimum $\operatorname{AIC}(M)$ value.

\section{Mean Absolute Percentage Error (MAPE)}

The Mean Absolute Percentage Error (MAPE) is a method for comparing forecasting accuracy by calculating the error of each forecast as a percentage of actual data. Absolute value is selected to measure the amount of error in calculating the percentage. MAPE in units of \% (percent) for the GSTAR model is stated as follows [4]:

$M A P E=\sum_{i=1}^{N} \sum_{i=2}^{T}\left[\left|\frac{\hat{e}_{i}(t)}{z_{i}(t)}\right|\right] \times \frac{1}{N(T-1)}$

where $z_{i}(t)$ the actual value and $\hat{e}_{i}(t)$ the error value of the $t$-th period at the $i$-th location.

\section{RESEARCH METHODS}

In this study, the data used are rainfall data from satellite extracts that have been re-analyzed from Climate Hazard Infra-Red Precipitation with Station (CHIRPS). This data is in the form of monthly rainfall data in the rainy season (December-January-February) in three (3) districts/cities (Bandung City, Cimahi City, and West Ban-dung Regency) in West Java with 36 years of observation (December 1981 February 2017, $n=108$ ). Based on research criteria and considerations, a sample of 108 data was divided into two parts, namely data for modeling (in sample) as many as 99 data and data for model validation (out sample) of 9 data.

The analysis technique used in this study is Vector Autoregressive (VAR). Analysis was carried out with the help of $\mathrm{R} \quad 3.5 .1$ 
programming language software. Steps in analyzing data, namely (1) Plot rainfall data in three regions; (2) Test data stationary with the Augmented Dickey-Fuller test; (3) Identify the model using the PACF plot and the smallest AIC value to find the optimum lag; (4) Carry out the Granger causality test to see reciprocal relation-ships between variables; (5) Perform parameter estimation using the Ordinary Least Square (OLS) method and significance parameters test with the t-test and F-test;
(6) Carry out diagnostic test models, including residual white noise test and heteroscedasticity test; (7) Forecast with the VAR model that has been obtained, then measuring the accuracy or feasibility of the model by comparing the value of Mean Absolute Percentage Error (MAPE) on the sample out data.

\section{RESULTS AND DISCUSSION}

\section{A. Data Plot}

The first step is to plot rainfall data from three locations of 99 data from December 1981 to February 2017.
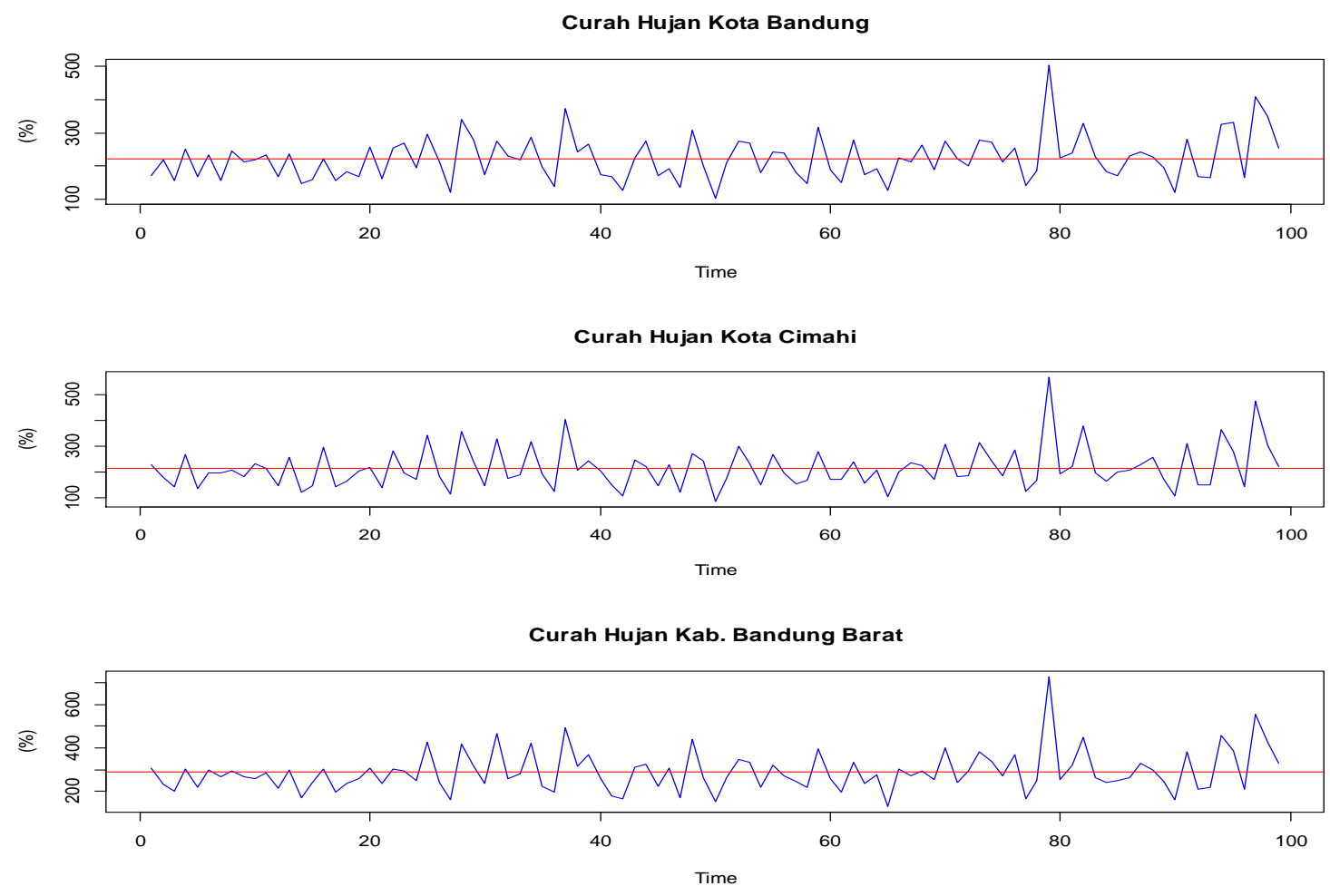

Fig. 1: Graph of rainfall data plots (source: processed products R.3.5.1)

Based on Fig. 1, it can be seen that rainfall movements in three locations tend to move fluctuatively up and down. In the 79th data, the intensity of rainfall is very high. The initial identification of the relationship of rainfall data in the three locations was carried out by looking at the Pearson correlation between locations. In Table 1 , it can be seen that the rainfall data at the locations correlates strongly with each other.

Table 1: Rainfall Correlation Value between Locations

\begin{tabular}{|l|c|c|c|}
\hline & $\begin{array}{c}\text { Bandung } \\
\text { City }\end{array}$ & Cimahi City & $\begin{array}{c}\text { West Bandung } \\
\text { Districts }\end{array}$ \\
\hline Bandung City & 1 & 0.92 & 0.94 \\
\hline Cimahi City & 0.92 & 1 & 0.96 \\
\hline West Bandung District & 0.94 & 0.96 & 1 \\
\hline
\end{tabular}

\section{B. Data Stationary}

Stationary data testing can be done using the Augmented Dickey Fuller (ADF) test to determine whether rainfall data from the three locations has a unit root or not. The ADF test calculation refers to equation (1). By using R 3.5.1 software, the results of the ADF test in Table 2 show that rainfall data in three stationary locations is in the mean. This can be seen from each location having a p-value less than the value of $\alpha=$ 0.05 , which means there is no unit root or stationary data. The following are the results of the ADF test of rainfall data for three locations in West Java Province.

Table 2: Augmented Dickey Fuller (ADF) Stationary Test Results

\begin{tabular}{|c|c|c|c|c|}
\hline \multirow{2}{*}{ Variable } & \multirow{2}{*}{$\begin{array}{c}\text { Data } \\
\text { Conditions }\end{array}$} & \multicolumn{3}{|c|}{ ADF Test } \\
\hline & & $t$-statistics & p-value & Conclusion \\
\hline $\begin{array}{l}\text { Bandung } \\
\text { City }\end{array}$ & $\begin{array}{c}\text { Original } \\
\text { (level) }\end{array}$ & -3.5142 & 0.04446 & Stationary \\
\hline $\begin{array}{l}\text { Cimahi } \\
\text { City }\end{array}$ & $\begin{array}{c}\text { Original } \\
\text { (level) }\end{array}$ & -3.5438 & 0.04183 & Stationary \\
\hline $\begin{array}{l}\text { West } \\
\text { Bandung } \\
\text { District }\end{array}$ & $\begin{array}{l}\text { Original } \\
\text { (level) }\end{array}$ & -3.6169 & 0.03532 & Stationary \\
\hline
\end{tabular}




\section{Model Identification}

The model identification process is carried out to get the optimum time lag order for the VAR model to be built. Early identification of the time lag order can be done based on the
PACF plot using stationary data in samples. The PACF test calculation refers to equation (3). By using R 3.5.1 software, the results of the PACF plot of each variable can be displayed in Fig. 2 below:

Kota Bandung

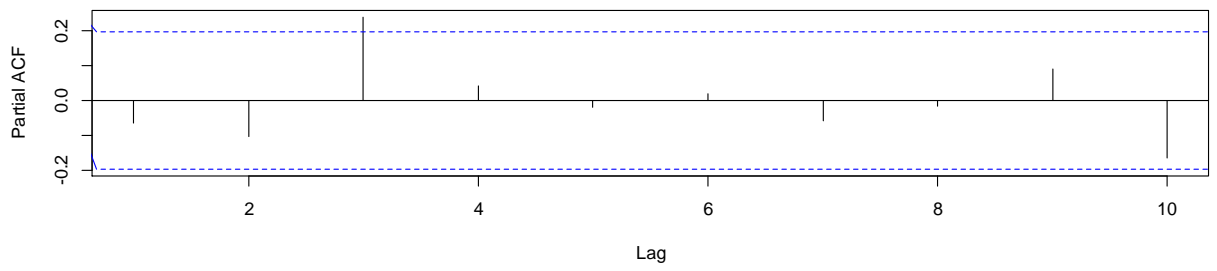

Kota Cimahi

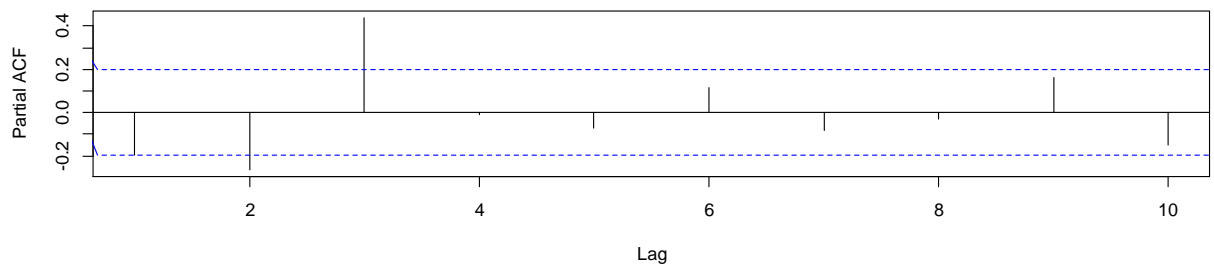

Kab. Bandung Barat

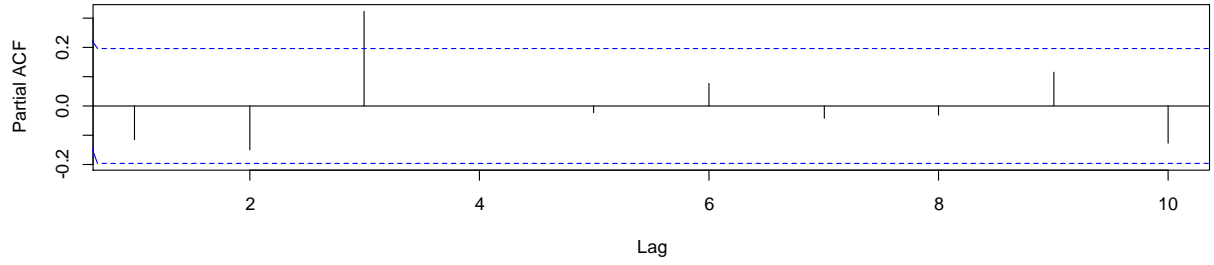

Fig. 2: Rainfall PACF plot graph

Fig. 2 above shows that the possibility of a lag order in the order of the VAR model is $(p=1)$, because three variables are cuts-off in the third lag. The determination of the optimal lag can also be done based on the smallest Akaike's Information Criterion (AIC) value. The AIC test calculation refers to equation (16). By using the R 3.5.1 software, the results of processing AIC can be shown in the following Table 3:

Table 3: Akaike's Information Criterion (AIC) Rainfall Data

\begin{tabular}{|c|c|c|c|}
\hline Lag & AIC & Lag & AIC \\
\hline 1 & 21,42505 & 6 & 20,24587 \\
\hline 2 & 20,75890 & 7 & 20,31112 \\
\hline 3 & $20,16429 *$ & 8 & 20,44860 \\
\hline 4 & 20,18337 & 9 & 20,53636 \\
\hline 5 & 20,19827 & 10 & 20,55978 \\
\hline
\end{tabular}

Based on Table 3 above the smallest AIC value lies in the 3rd lag, so the optimum order that will be used in the VAR model is VAR(3). The equation for the VAR model (3) is as follows:

$$
\begin{aligned}
\hat{Z}_{1}(t) & =\phi_{10}+\phi_{11} Z_{1}(t-1)+\phi_{12} Z_{2}(t-1)+\phi_{13} Z_{3}(t-1) \\
& +\phi_{14} Z_{1}(t-2)+\phi_{15} Z_{2}(t-2)+\phi_{16} Z_{3}(t-2) \\
& +\phi_{17} Z_{1}(t-3)+\phi_{18} Z_{2}(t-3)+\phi_{19} Z_{3}(t-3)+a_{1}(t)
\end{aligned}
$$

$$
\begin{aligned}
\hat{Z}_{2}(t) & =\phi_{20}+\phi_{11} Z_{1}(t-1)+\phi_{22} Z_{2}(t-1)+\phi_{23} Z_{3}(t-1) \\
& +\phi_{24} Z_{1}(t-2)+\phi_{25} Z_{2}(t-2)+\phi_{26} Z_{3}(t-2) \\
& +\phi_{27} Z_{1}(t-3)+\phi_{28} Z_{2}(t-3)+\phi_{29} Z_{3}(t-3)+a_{2}(t) \\
\hat{Z}_{3}(t) & =\phi_{30}+\phi_{31} Z_{1}(t-1)+\phi_{32} Z_{2}(t-1)+\phi_{33} Z_{3}(t-1) \\
& +\phi_{34} Z_{1}(t-2)+\phi_{35} Z_{2}(t-2)+\phi_{36} Z_{3}(t-2) \\
& +\phi_{37} Z_{1}(t-3)+\phi_{38} Z_{2}(t-3)+\phi_{39} Z_{3}(t-3)+a_{3}(t)
\end{aligned}
$$

In the form of a matrix, the above equation can be written as follows:

$$
\begin{aligned}
{\left[\begin{array}{l}
\hat{Z}_{1} \\
\hat{Z}_{2} \\
\hat{Z}_{3}
\end{array}\right]=} & {\left[\begin{array}{l}
\phi_{10} \\
\phi_{20} \\
\phi_{30}
\end{array}\right]+\left[\begin{array}{lll}
\phi_{11} & \phi_{12} & \phi_{13} \\
\phi_{21} & \phi_{22} & \phi_{23} \\
\phi_{31} & \phi_{32} & \phi_{33}
\end{array}\right]\left[\begin{array}{l}
Z_{1}(t-1) \\
Z_{2}(t-1) \\
Z_{3}(t-1)
\end{array}\right] } \\
& +\left[\begin{array}{lll}
\phi_{14} & \phi_{15} & \phi_{16} \\
\phi_{24} & \phi_{25} & \phi_{26} \\
\phi_{34} & \phi_{35} & \phi_{36}
\end{array}\right]\left[\begin{array}{l}
Z_{1}(t-2) \\
Z_{2}(t-2) \\
Z_{3}(t-2)
\end{array}\right] \\
& +\left[\begin{array}{lll}
\phi_{17} & \phi_{18} & \phi_{19} \\
\phi_{27} & \phi_{28} & \phi_{29} \\
\phi_{37} & \phi_{38} & \phi_{39}
\end{array}\right]\left[\begin{array}{l}
Z_{1}(t-3) \\
Z_{2}(t-3) \\
Z_{3}(t-3)
\end{array}\right]+\left[\begin{array}{l}
a_{1}(t) \\
a_{2}(t) \\
a_{3}(t)
\end{array}\right]
\end{aligned}
$$




\section{Granger Causality}

The Granger causality test is used to see the past influence of a location on the current condition of another location. The presence or absence of this causality relationship is tested through the $\mathrm{F}$ test or its probability value ( $p$-value). The calculation of the Granger causality test refers to equation (8) and equation (9). By using the R 3.5.1 software, the results of the Granger causality test are shown in the following Table 4:

Table 4: Fstat and Probability Values in Granger Causality Test

\begin{tabular}{|l|c|c|}
\hline \multirow{2}{*}{$\boldsymbol{H}_{\mathbf{0}}$} & \multicolumn{2}{c|}{ Lag 3 } \\
\cline { 2 - 3 } & $F_{\text {stat }}$ & Prob \\
\hline CH_Bandung does not Granger CH Cimahi & 3,2241 & $\mathbf{0 , 0 2 6 3}$ \\
\hline CH_Bandung does not Granger CH Bandung Barat & 2,1259 & 0,1026 \\
\hline CH_Cimahi does not Granger CH Bandung & 5,4748 & $\mathbf{0 , 0 0 1 7}$ \\
\hline CH_Cimahi does not Granger CH Bandung Barat & 2,1943 & $\mathbf{0 , 0 9 4 3}$ \\
\hline CH_Bandung Barat does not Granger CH Bandung & 1,5061 & 0,2184 \\
\hline CH_Bandung Barat does not Granger CH Cimahi & 2,5372 & $\mathbf{0 , 0 6 1 7}$ \\
\hline
\end{tabular}

Based on Table 4 above, at the $10 \%$ significance level shows that between rainfall in Bandung City and Cimahi City and Cimahi City and West Bandung District has a two-way causality relationship. In other words, the rainfall in Bandung in the previous period can contribute to predict the rainfall of Cimahi City at this time, and vice versa. The same thing happens between rainfall in Cimahi City and rainfall in West Bandung District.

\section{E. Estimate and Test for Parameter Significance}

From the results of previous tests, the model chosen based on optimum lag is VAR (3). The model explains that a location is not only influenced by the previous three periods in that location but also influenced by the previous three periods in other locations. The method used in estimating parameters in this study is the Ordinary Least Square (OLS) method. Then to test the level of parameter estimate using the t-test partially and the F-test simultaneously. Calculation of parameter estimates with the OLS method refers to equation (5). By using the R 3.5.1 software, the results of calculation of parameter estimation of the VAR model (3) in Table 5 show that by using the $10 \%$ significance level, the three equations are significant simultaneously.

Table 5: Parameter Estimation Results of the VAR Model (3)

\begin{tabular}{|c|c|c|c|c|}
\hline Variable & Parameter & Estimate & $t$-value & $\begin{array}{c}\mathrm{p} \text {-value } \\
\text { (simultaneous) }\end{array}$ \\
\hline \multirow{9}{*}{$\begin{array}{c}\text { Bandung } \\
\left(\hat{Z}_{1}(t)\right)\end{array}$} & $\phi_{10}$ & 191.41899 & 4.311 & \multirow{9}{*}{0.04327} \\
\hline & $\phi_{11}$ & -0.42205 & -0.960 & \\
\hline & $\phi_{12}$ & 0.53016 & 1.267 & \\
\hline & $\phi_{13}$ & -0.06079 & -0.179 & \\
\hline & $\phi_{14}$ & 0.12432 & 0.286 & \\
\hline & $\phi_{15}$ & 0.10310 & 0.238 & \\
\hline & $\phi_{16}$ & -0.20214 & -0.579 & \\
\hline & $\phi_{17}$ & -0.64056 & -1.553 & \\
\hline & $\phi_{18}$ & 0.63425 & 1.504 & \\
\hline
\end{tabular}

\begin{tabular}{|c|c|c|c|c|}
\hline & $\phi_{19}$ & 0.15545 & 0.461 & \\
\hline \multirow{10}{*}{$\begin{array}{l}\text { Cimahi } \\
\left(\hat{Z}_{2}(t)\right)\end{array}$} & $\phi_{20}$ & 173.45347 & 3.884 & \multirow{10}{*}{$2.195 \mathrm{e}-07$} \\
\hline & $\phi_{21}$ & -0.29793 & -0.674 & \\
\hline & $\phi_{22}$ & 0.16237 & 0.386 & \\
\hline & $\phi_{23}$ & 0.09551 & 0.280 & \\
\hline & $\phi_{24}$ & 0.33736 & 0.772 & \\
\hline & $\phi_{25}$ & -0.08427 & -0.193 & \\
\hline & $\phi_{26}$ & -0.20939 & -0.596 & \\
\hline & $\phi_{27}$ & -1.02917 & -2.481 & \\
\hline & $\phi_{28}$ & 1.28149 & 3.020 & \\
\hline & $\phi_{29}$ & 0.01551 & 0.046 & \\
\hline \multirow{10}{*}{$\begin{array}{l}\text { WBD } \\
\left(\hat{Z}_{3}(t)\right)\end{array}$} & $\phi_{30}$ & 236.30150 & 3.969 & \multirow{10}{*}{0.00273} \\
\hline & $\phi_{31}$ & -0.14986 & -0.254 & \\
\hline & $\phi_{32}$ & 0.28749 & 0.512 & \\
\hline & $\phi_{33}$ & -0.11318 & -0.248 & \\
\hline & $\phi_{34}$ & 0.14178 & 0.244 & \\
\hline & $\phi_{35}$ & 0.13183 & 0.227 & \\
\hline & $\phi_{36}$ & -0.21833 & -0.466 & \\
\hline & $\phi_{37}$ & -0.90705 & -1.640 & \\
\hline & $\phi_{38}$ & 1.25832 & 2.225 & \\
\hline & $\phi_{39}$ & -0.02181 & -0.048 & \\
\hline
\end{tabular}

In the form of a matrix, the VAR model (3) above can be written as follows:

$$
\begin{aligned}
{\left[\begin{array}{l}
\hat{Z}_{1} \\
\hat{Z}_{2} \\
\hat{Z}_{3}
\end{array}\right] } & {\left[\begin{array}{l}
191.41889 \\
173.45347 \\
236.30150
\end{array}\right]+\left[\begin{array}{ccc}
-0.42205 & 0.53016 & -0.06079 \\
-0.29793 & 0.16237 & 0.09551 \\
-0.14986 & 0.287469 & -0.11318
\end{array}\right] } \\
& {\left[\begin{array}{l}
Z_{1}(t-1) \\
Z_{2}(t-1) \\
Z_{3}(t-1)
\end{array}\right]+\left[\begin{array}{ccc}
0.12432 & 0.10310 & -0.20214 \\
0.33736 & -0.08427 & -0.20939 \\
0.14178 & 0.13183 & -0.21833
\end{array}\right]\left[\begin{array}{c}
Z_{1}(t-2) \\
Z_{2}(t-2) \\
Z_{3}(t-2)
\end{array}\right] } \\
& +\left[\begin{array}{lll}
-0.64056 & 0.63425 & 0.15545 \\
-1.02917 & 1.28149 & 0.01551 \\
-0.90705 & 1.25832 & -0.02181
\end{array}\right]\left[\begin{array}{c}
Z_{1}(t-3) \\
Z_{2}(t-3) \\
Z_{3}(t-3)
\end{array}\right]+\left[\begin{array}{l}
a_{1}(t) \\
a_{2}(t) \\
a_{3}(t)
\end{array}\right]
\end{aligned}
$$$$
\text { with assumption } a_{1}(t), a_{1}(t), a_{1}(t) \sim \text { iid } N\left(\mu, \sigma^{2}\right) \text {. }
$$

\section{F. Model Diagnostic}

Diagnostic tests are conducted to determine the feasibility of the model. Model is declared feasible if between residuals are free from each other (white noise), the residual range is normally distributed, and there is no ARCH effect (constant residual).

\section{White Noise Residual Test}

The hypothesis used to test residual white noise is: $H_{0}: E\left(\varepsilon_{t}, \varepsilon_{t-i}\right)=0$, (the model meets residual white noise), $H_{1}$ : at least one $E\left(\varepsilon_{t}, \varepsilon_{t-i}\right) \neq 0$, (the model does not meet residu-al white noise).

Residual white noise testing is carried out by the Portmanteau test through equation (10). By using the R 3.5.1 software, the results obtained are as follows: 


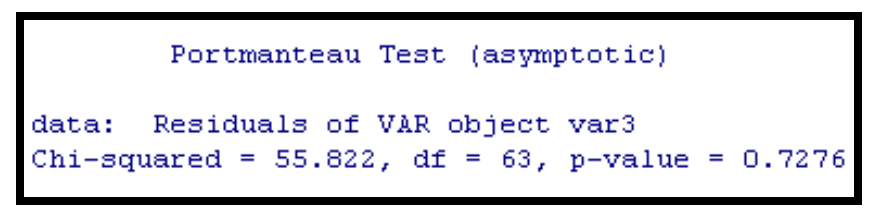

Fig. 3: White noise residual test results

with a $10 \%$ significance level, it is found that reject $\mathrm{H} 1$ (p-value > 0.10). So that the VAR model (3) meets the requirements of the White Noise Residual.

\section{Heteroscedasticity Test}

The hypothesis used to test residual homogeneity is:

$H_{0}$ : residual variances are homogeneous,

$H_{1}$ : residual variances are not homogeneous.

Heterocedasticity testing is done by Lagrange Multiplier (LM) test through equation (11) and equation (12). By using the R 3.5.1 software, the results obtained are as follows:

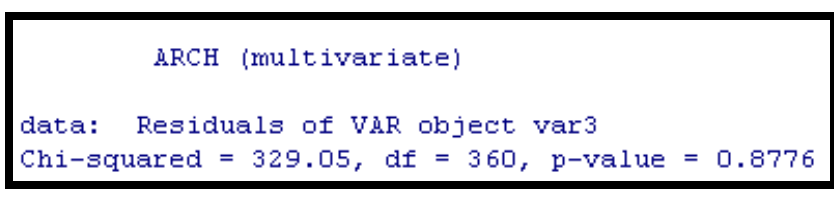

Fig. 4: Heteroscedasticity test results

with a $10 \%$ significance level of $10 \%$, the LM $0.8776>0.10$ is obtained. So $\mathrm{H} 1$ is rejected, which means that the residual is homogeneous. The results of the diagnostic test on residuals indicate that the VAR (3) model has met residual homogeneity and residual white noise residuals.

\section{G. Accuracy of Prediction og the VAR Model (3)}

The next analysis is looking at a comparison of the accuracy or accuracy of forecasting from the VAR model (3) in forecasting three locations of rainfall data in West Java. Determining the best model is done by comparing the value of Mean Absolute Percent-age Error (MAPE). The MAPE value in the out sample is used to see how accurate the estimation is in a model. The forecasting results for 9 months for each location are as follows:

Actual and Rainfall Forecasting in Bandung City

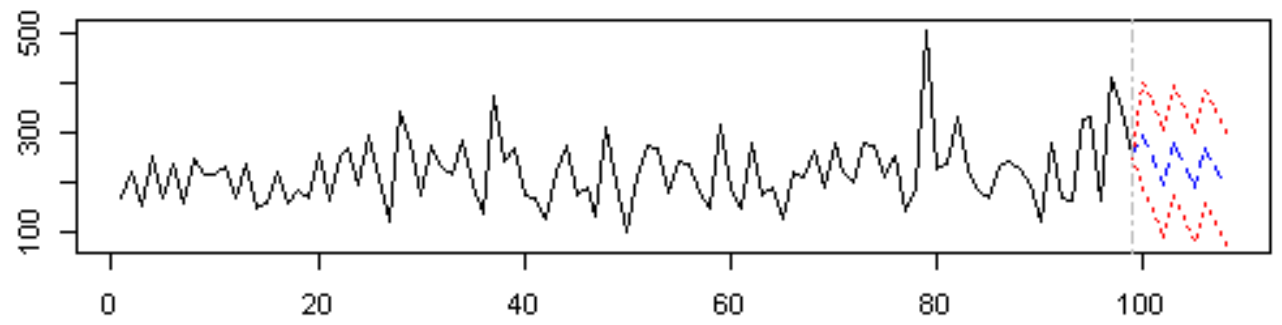

Actual and Rainfall Forecasting in Cimahi City

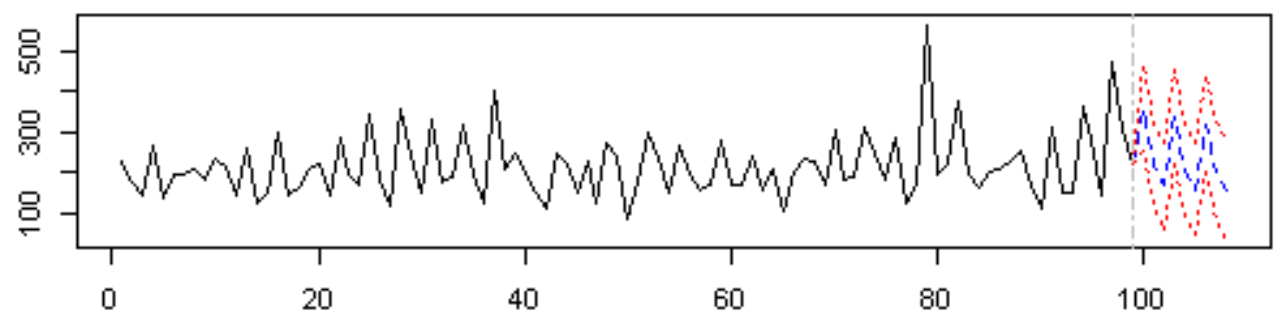

Actual and Rainfall Forecasting in West Bandung District

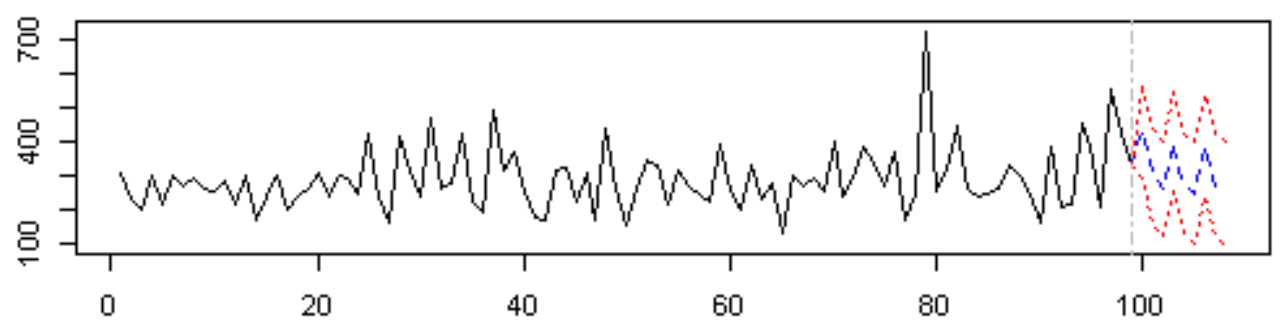

Fig. 5: Data Actual and Prediction Model VAR (3) Plot Chart

Based on Fig. 5 above, it can be seen that the pattern of rainfall estimates for three locations in West Java with the VAR model (3). The pattern has a tendency in the form of toothed lines and has a pattern similar to previous periods. This indicates that the VAR (3) model that has been formed is good for obtaining the forecast value.
This is made clear by calculating the MAPE value for the three locations. The calculation of the MAPE value refers to equation (17). By using the R 3.5.1 software, the results of the MAPE calculation obtained are as follows: 
Table 6: MAPE VAR Model Value (3) between Actual Value and Prediction Value

\begin{tabular}{|l|c|c|c|c|c|c|c|c|c|}
\hline \multirow{2}{*}{ Month } & \multicolumn{3}{|c|}{ Bandung City } & \multicolumn{3}{c|}{ Cimahi City } & \multicolumn{2}{c|}{ West Bandung District } \\
\cline { 2 - 11 } & $\begin{array}{c}\text { Actua } \\
1\end{array}$ & Forecast & MAPE & $\begin{array}{c}\text { Actua } \\
1\end{array}$ & Forecast & MAPE & $\begin{array}{c}\text { Actua } \\
1\end{array}$ & Forecast & MAPE \\
\hline Dec-14 & 315 & 294 & 0.07 & 336 & 360 & 0.07 & 397 & 432 & 0.09 \\
\hline Jan-15 & 211 & 256 & 0.21 & 174 & 221 & 0.27 & 226 & 297 & 0.31 \\
\hline Feb-15 & 265 & 198 & 0.25 & 227 & 167 & 0.26 & 355 & 263 & 0.26 \\
\hline Dec-15 & 262 & 283 & 0.08 & 282 & 339 & 0.20 & 327 & 403 & 0.23 \\
\hline Jan-16 & 171 & 238 & 0.39 & 141 & 205 & 0.45 & 199 & 278 & 0.40 \\
\hline Feb-16 & 235 & 191 & 0.19 & 204 & 159 & 0.22 & 316 & 249 & 0.21 \\
\hline Dec-16 & 263 & 271 & 0.03 & 277 & 321 & 0.16 & 301 & 386 & 0.28 \\
\hline Jan-17 & 240 & 234 & 0.03 & 192 & 202 & 0.05 & 258 & 273 & 0.06 \\
\hline Feb-17 & 167 & 189 & 0.13 & 144 & 157 & 0.09 & 229 & 246 & 0.07 \\
\hline & \multicolumn{6}{|c|}{ MAPE (\%) } & $\mathbf{1 5 . 3 2 4}$ & \multicolumn{3}{|c|}{ MAPE (\%) } & $\mathbf{1 9 . 8 1 9}$ & MAPE (\%) & $\mathbf{2 1 . 3 0 7}$ \\
\hline
\end{tabular}

Based on Table 6 above, MAPE values obtained from forecasting rainfall data for each location with the VAR model (3), namely Bandung City at 15,324 percent, Cimahi City at 19,819 percent, and West Bandung District at 21,307 percent. While the average MAPE value obtained from the three locations is 18,817 percent or less than $20 \%$, which means that the VAR model (3) is quite feasible to be used as forecasting rainfall for the three locations.

\section{CONCLUSION}

In this paper, research has been carried out on rainfall forecasting using the VAR model in three locations in West Java, namely Ban-dung City, Cimahi City, and West Bandung District. Based on the results of the study it can be concluded that the characteristics of rainfall in three locations have the same tendency seen from the plot of data and high correlation values. The results of the causality test show that there is a contribution between locations in providing rainfall influence between one location and another location. The estimation results and parameter significance tests show that rainfall in three locations significantly follows the VAR model (3). The estimator on the VAR model (3) is then used to forecast rainfall in three locations for the next 9 periods. The forecasting has a MAPE error rate in Bandung City of 15,324 percent, Cimahi City of 19,819 percent, and West Bandung Distict at 21,307 percent or the average value of MAPE from the three locations amounting to 18,817 percent. So that the VAR model (3) is sufficiently feasible to forecast rainfall in these three locations because it has an MAPE value below 20\%. The forecasting results are expected to help the government and the community as an anticipation step if there is a high intensity of rainfall.

\section{ACKNOWLEDGMENT}

Acknowledgments are conveyed to the Rector, Director of Directorate of Research, Community Involvement and Innovation, and the Dean of Faculty of Mathematics and Natural Sciences, Universitas Padjadjaran, which has been providing facilities and infrastructure to conduct this research.

\section{REFERENCES}

1. H. Akaike, "Information Theory and the Maximum Likelihood Principle in Second International Symposium on Information Theory," in B.N. Petrov and F. Cs a ki. Akademiai Kiado, Budapest, 1973.

2. S. Aldrian, "Identification of three dominant rainfall regions within Indo-nesia and their relationship to sea surface temperature," in Int. J. Clim., vol. 23, 2003, pp. 1435-1452.

3. W. Enders, Applied Econometric Time Series Third Edition. John Wiley and Sons: New York, 2010.

4. B. N. Ruchjana, Suatu model Generalisasi Space TimeAutoregressive dan pen-erapannya pada produksi minyak bumi. Dissertation: unpublished, ITB: Bandung, 2002

5. S. Ankamah, "Modelling Trends of Climatic Variability and Malaria in Ghana Using Vector Autoregression," Article ID 6124321, 2018.

6. A. Nugroho and Subanar, "Vector Autoregression (VAR) Model for Rainfall Forecast and Isohyet Mapping in Semarang - Central Java Indonesia," in International Journal of Advanced Computer Science and Aplications (IJACSA), vol. 5, no. 11, 2014.

7. D. Chapman, "A Vector Autoregressive ENSO Prediction Model," in Journal of Climate, vol. 28, 2015.

8. H. Abdul and Tarno, "Vector Autoregressive Model Approach for Forecasting Out-flow Cash in Central Java," in Journal of Physics: Conf. Ser., 1025012105, 2018.

9. Y. K. Chai, "Application of Vector Autoregressive Model for Rainfall and Groundwater Level Analysis," in AIP Conference Proceedings, vol. $1870,2017$.

10. S. Mangiarroti and M. Sekhar, "Causality Analysis of Groundwater Dynamics based on a Vector Autoregressive Model in the Semi-Arid Basin of Gundal (South India)," in Journal of Applied Geophysics, vol. 83, no. 1-10, 2012.

11. S. Hartini, M. Hadi M, and Pramono, "Application of Vector Auto Regression Model for Rainfall-River Discharge Analysis," in Indonesian Journal of Spatial and Regional Analysis, vol. 29(1), 2015.

12. R. Dewi, Dhamar, and W. Purnami, "Vector Autoregressive Generalized Space Time Autoregressive (VAR-GSTAR) Model with 2-Means Clustering on Rainfall of Central Java," in ICAS, ISSN: 2579-4361, 2016.

13. W. W. S. Wei, Time Series Analysis: Univariate and Multivariate Methods, 2nd edition. Pearson Prentice Hall: New Jersey, 2006.

14. E. J. Hannan, Multiple Time Series. John Wiley and Sons: New York, 1970 . 